\title{
Amaleena Damlé, Gill Rye (ed.), Aventures et expériences littéraires. Écritures des femmes en France au début du vingt-et-unième siècle
}

\section{Francesca Forcolin}

\section{(2) OpenEdition \\ Journals}

\section{Edizione digitale}

URL: http://journals.openedition.org/studifrancesi/685

DOI: $10.4000 /$ studifrancesi.685

ISSN: 2421-5856

\section{Editore}

Rosenberg \& Sellier

\section{Edizione cartacea}

Data di pubblicazione: 1 aprile 2015

Paginazione: 214-215

ISSN: 0039-2944

\section{Notizia bibliografica digitale}

Francesca Forcolin, « Amaleena Damlé, Gill Rye (ed.), Aventures et expériences littéraires. Écritures des femmes en France au début du vingt-et-unième siècle », Studi Francesi [Online], 175 (LIX | I) | 2015, online dal 01 avril 2015, consultato il 18 septembre 2020. URL : http://journals.openedition.org/ studifrancesi/685; DOI : https://doi.org/10.4000/studifrancesi.685

\section{Questo documento è stato generato automaticamente il 18 settembre 2020.}

\section{cc) $($ ) $\ominus$}

Studi Francesi è distribuita con Licenza Creative Commons Attribuzione - Non commerciale - Non opere derivate 4.0 Internazionale. 


\title{
Amaleena Damlé, Gill Rye (ed.), Aventures et expériences littéraires. Écritures des femmes en France au début du vingt-et-unième siècle
}

\author{
Francesca Forcolin
}

\section{NOTIZIA}

AMALEENA DAMLÉ, GILL RYE (ed.) Aventures et expériences littéraires. Écritures des femmes en France au début du vingt-et-unième siècle, New York, Rodopi, 2014, pp. 333.

1 Provocatrici, estreme, le autrici del nuovo millennio amano suscitare scandalo e scalpore attraverso una scrittura in cui l'io si svela così, nudo, impudico, senza veli. Una prima persona narrativa difficilmente etichettabile poiché, nella maggior parte dei casi, finzione e realtà vengono mescolate creando un brouillage tra i generi. Le autrici del nuovo millennio si interrogano sulla nozione di identità, narrando sia esperienze personali sia collettive; inventano giochi linguistici ed estetici creando pratiche ambigue; sperimentano, osano. L'identità femminile non è affermata, bensì messa in discussione, e i lati più oscuri esplorati: l'aborto, il sesso, la violenza. Eredi dell'emancipazione degli anni '70 (Cixous, Chawaf, Leclerc), le autrici di tale discorso osceno - ob/scenus, che deve restare fuori dalla scena - intendono sovvertire quello patriarcale e fallocentrico: ma è proprio grazie al padre, simbolo dell'autorità, dell'ordine, della forza, che la scrittura si genera.

2 È intorno alla figura del padre, infatti, che ruotano le opere analizzate nella prima metà del volume, nella sezione intitolata «Aventures auto/biographiques», che si apre con una delle scritture più controverse degli ultimi anni: quella di Christine Angot, "regina dell'autofiction", nella cui scrittura l'io, secondo l'opinione di gran parte della critica, tende a un ripiegamento narcisistico. Non per Anne-Marie PICARD che, in La 'singlerie' de 
l'écrivain, au-delà du leurre de l'identité: Christine Angot (pp. 21-37), analizza la rilettura della fiaba di Perrault Peau d'âne, adattata all'esperienza incestuosa vissuta dal je con il padre. Un io ossessivo e insistente che, attraverso un movimento, ci dice l'A., vissuto come una castrazione, desacralizza il proprio trauma «pour prétendre à l'universalité que permet la littérature»: dal presunto individualismo a un'apertura all'altro e alla società. La violenza esercitata dalla figura paterna torna, esplicita, nella scrittura di Chloé Delaume: in Le cri du sablier del 2001, testo autofictif di ispirazione oulipiana per il lavoro ludico e sperimentale sulla lingua, l'autrice narra l'atto irreversibile - in quanto omicida - del padre (Dérouter le lecteur: procédés stylistiques dans "Le cri du sablier" de Chloé Delaume, di Valérie DUSAILLANT-FERNANDES, pp. 39-56). È particolarmente evidente l'io autobiografico come apertura all'altro, piuttosto che espressione di sterile narcisismo, nella scrittura di Annie Ernaux, analizzata nei due contributi successivi: Annie Ernaux et la photo-socio-biographie: vers une écriture du "dehors" di Fabien ARRIBERT-NARCE (pp. 57-74) e "Les Années", une autobiographie collective: Annie Ernaux ou l'art littérairement distinctif du paradoxe di Isabelle CHARPENTIER, grande studiosa dell'autrice (pp. 75-92). In particolare, il ricorso alla fotografia in L'Usage de la photo e in Les années fa sfociare l'autobiografismo di Ernaux in una dimensione impersonale e collettiva, dove il je è piuttosto un nous. Il rapporto padre-figlia in Le récit siamois dans "Personne" de Gwenaëlle Aubry (pp. 93-106), costruisce quello che Laureline AMANIEUX definisce il «racconto siamese»: infatti, G. Aubry fa coesistere nello stesso racconto due intrighi, la storia del padre e della figlia, che si modellano su rapporti conflittuali, creando una forma narrativa doppia siamese, appunto. Spesso, però, il rapporto padre/figlia è difficoltoso, il dialogo inesistente, dominato dal silenzio, come nella scrittura di Nathalie Rheims analizzata da un'altra grande studiosa della scrittura femminile, Catherine RODGERS (Silence du père, écriture de la fille dans "Les fleurs du silence" de Nathalie Rheims, pp. 107-123). Una caratteristica preponderante della scrittura femminile degli ultimi anni è la forte presenza del corpo, un'intimità impudica dove il desiderio si apre e si mette a nudo sulla pagina: è una geografia dei sentimenti in un eccesso provocatorio quella che ci è offerta da Nina Bouraoui, come ci spiega Amaleena DAMLÉ in «Multiple et changeante»: amour, connaissance et fragilité dans "Nos baisers sont des adieux" de Nina Bouraoui (pp. 125-141).

3 Nella seconda sezione, «Aventures sociales, politiques et philosophiques», i contributi si soffermano sui rapporti familiari, sociali (come le problematiche legate all'immigrazione), sulla degradazione del corpo dovuta alla vecchiaia e alla malattia. Nel primo contributo, Ni victime ni coupable: Virginie Despentes, de la pratique littéraire à la théorie (pp. 145-159), Virginie SAUZON analizza la violenza subita dalle donne prendendo come riferimento l'opera di Despentes: il rapporto di forza tra due soggetti, la dominazione, la confusione tra vittima e colpevole, sono tutti temi che fanno da motore a molteplici scritture (Christine Angot in primis). Si passa poi al rapporto coniugale e alla sua evoluzione contemporanea dettata dalle nuove tendenze socio-culturali: problematiche affrontate da France GRENAUDIER-KLIJN nell'analisi comparativa messa a punto in Ciel mon mari! Le conjugal chez Catherine Cusset, Agnès Desarthe et Alice Ferney (pp. 161-176). Sempre in seno alla famiglia troviamo un altro rapporto, quello tra fratello e sorella, preso raramente in considerazione ma ottimo punto di partenza per l'analisi delle rivalità e complicità tra uomo e donna. Lori SAINT-MARTIN, in Le rapport frère-sœur comme signe de la mixité dans le roman français contemporain des femmes (pp. 177-194), lo esplora attraverso lo studio di sei scritture (Fleutiaux, Ladjali, Wolinski, Lafon, Vigourt, 
Herzog). Cécilia GIL si sofferma invece sulla vecchiaia, o meglio sul decadimento del corpo, sia nel rapporto con il sé che con l'altro (Écrire la veillesse dans l'œuvre de Régine Detambel, pp. 195-211). Il tema dell'immigrazione è affrontato nei contributi che seguono: in 'Etrangères à elles-mêmes': l'immigration en France chez les nouvelles écrivaines francophones, Alison RICE (pp. 213-229) analizza tre scrittrici francofone, N. Appanah, F. Diome e S. Sinha, ognuna con le proprie esperienze legate all'allontanamento della terra natìa; Marie CARRIÈRE approfondisce invece Petroleum del 2004 di Bessora, dove il colonialismo e in particolare la storia del Gabon sono rivisti attraverso il mito di Medea ("Petroleum" de Bessora: une mythopoésis postcoloniale, pp. 231-249). La perdita identitaria diventa simbolica con la perdita della forma, cioè con la trasformazione del corpo: un superamento dei limiti umani che si può osservare nelle opere Mon cœur à l'étroit e En famille di Marie NDiaye, come ci spiega Thangam RAVINDRANATHAN in Le destin secret de la chair: réflexions sur deux récits de Marie NDiaye, (pp. 251-266). Dal decadimento alla disumanizzazione, infine la morte: Marinella TERMITE sonda la nozione di "fine" in alcune opere contemporanee, tra ripiegamento soggettivo e visioni apocalittiche (Le goût de la fin: de Michèle Desbordes à Céline Minard, pp. 267-282). Seguono la bibliografia e le note sugli autori dei contributi, in questo ricco volume che propone una buona panoramica della scrittura femminile contemporanea, tema già sondato più volte ma che qui sembra aprirsi a una riflessione più approfondita. 